\title{
Environmental Risk Factors and Work-Related Lower Respiratory Symptoms in 80 Office Buildings: An Exploratory Analysis of NIOSH Data
}

\section{Authors:}

Mark J. Mendell, PhD, MPH

Indoor Environment Department, Environmental Energy Technologies Division, Lawrence Berkeley National Laboratory,

Gina M. Naco, MPH

(no affiliation)

Thomas G. Wilcox, MD

Office of Field Programs, Center for Food Safety and Applied Nutrition, U.S.

Food and Drug Administration

W. Karl Sieber, PhD

Division of Surveillance, Hazard Evaluations, and Field Surveys, National

Institute for Occupational Safety and Health

\section{Institute at which performed:}

Data collection, analysis, and most of the production of this manuscript were performed while all authors were with the National Institute for Occupational Safety and Health in Cincinnati, $\mathrm{OH}$.

\section{Author for correspondence:}

Mark J. Mendell, PhD, MPH

Lawrence Berkeley National Laboratory

1 Cyclotron Road, MS 90-3058

Berkeley, CA 94720

PH: 510-486-6591

FX: 510-486-6658

e-m: mjmendell@1bl.gov

\section{Short title:}

Risks for Respiratory Symptoms in Offices

\section{Financial Support:}

This work was supported by the National Institute for Occupational Safety and Health, and by the Assistant Secretary for Energy Efficiency and Renewable Energy, Office of Building Technology, State, and Community Programs, Office of Building Research and Standards of the U.S. Department of Energy (DOE) under contract No. DE-AC03-76SF00098. 


\begin{abstract}
Background: We evaluated relationships between lower respiratory symptoms and risk factors for microbiological contamination in office buildings.

Methods: The National Institute for Occupational Safety and Health collected data from 80 office buildings during standardized indoor environmental health hazard evaluations. Present analyses included lower respiratory symptom-based outcome definitions and risk factors for potential microbiologic contamination. Multivariate logistic regression models for selected outcomes identified key risk factors.

Results: Adjusted odds ratios (95\% confidence intervals) for "at least three of four work-related lower respiratory symptoms" were, for debris in ventilation air intake, 2.0 (1.0-3.9), and for poor drainage in air-conditioning drip pans, 2.6 (1.3-5.2). Adjusted associations with risk factors were consistently stronger for outcomes requiring both multiple symptoms and improvement away from work, and somewhat stronger among diagnosed asthmatics.

Conclusions: Moisture and debris in ventilation systems, possibly by supporting microbiologic growth, may increase adverse respiratory effects, particularly among asthmatics. Data from more representative buildings are needed to confirm these findings.

\section{Key words:}

indoor environmental quality, indoor air quality, sick building syndrome, nonspecific symptoms, respiratory symptoms, respiratory disease, ventilation systems, building-related illness, asthma
\end{abstract}




\section{Background}

A defined disease involving a specific medical diagnosis attributable to specific exposure in a building is often referred to as a building-related illness (BRI). Documented BRI in indoor, nonindustrial workplaces such as office buildings has been reported occasionally [Hodgson et al., 1987; Hoffman et al., 1993; Jarvis and Morey, 2001; Kreiss, 1989; Seuri et al., 2000]. Most reported episodes have involved respiratory disease such as hypersensitivity pneumonitis or humidifier fever associated with microbiologic contamination of the indoor environment [e.g., Hodgson et al., 1987].

In contrast, episodes of nonspecific health complaints in indoor workplaces, not attributable to specific recognized disease or exposures, have been very commonly reported in recent decades [Mendell, 1993]. Sometimes referred to as sick building syndrome (SBS), these episodes have involved widespread complaints of symptoms and discomfort, including mucous membrane irritation, nasal symptoms, skin irritation, headache, fatigue, and sometimes breathing problems. These symptoms are often reported to occur in the building and to diminish away from the building. The nonspecific symptoms involved in so-called SBS have generally not been associated with physical findings on clinical examination or abnormalities in laboratory tests [Kreiss, 1989]. In practice, SBS generally refers to any cluster of building-related health complaints that cannot be characterized as a recognized BRI.

Although specific causal exposures for nonspecific building-related symptoms have not yet been established, research has identified a number of person-, job-, workplace-, and building-related risk factors for these symptoms (e.g., presence of air-conditioning systems, low ventilation rate, high temperature, dust, endotoxin) [Gyntelberg et al., 1994; Mendell, 1993; Teeuw et al., 1994]. Much research has associated moisture, mold, and related factors in residential environments with upper and lower respiratory symptoms [Bornehag et al., 2001]. Available evidence suggests that multiple biologic response mechanisms may ultimately be identified as underlying non-specific building-related symptoms, presenting with overlapping sets of symptoms yet resulting from different single or combined indoor exposures. Researchers have often treated the multiple symptoms reported in buildings as a single syndrome [e.g., Burge et al., 1987], although some researchers have considered sub-syndromes such as central nervous systems and mucus membrane irritation symptoms [Jaakkola and Miettinen, 1995; Mendell et al., 1996]. Few reports have considered lower respiratory symptoms, which have been the least commonly reported symptoms studied in indoor environments [Mendell et al., 1996; Ruotsalainen et al., 1995; Sieber et al., 1996].

Recent studies have reported the association of risk factors in non-industrial indoor environments with increased work-related lower respiratory symptoms [Mendell et al., 1996; Ruotsalainen et al., 1995; Sieber et al., 1996]. For this analysis, we hypothesized that microbiologic contamination of indoor spaces or ventilation systems in office buildings may cause or exacerbate unrecognized building-related respiratory disease that presents as work-related lower respiratory symptoms.

The objective of this analysis was to identify, as indicators of an underlying physiologic response, respiratory symptom-based outcome definitions that have the strongest associations 
with previously identified risk factors for microbiological contamination. Variations in the definitions assessed included: requiring different numbers and combinations of symptoms in the definition; restricting symptoms to those exacerbated at work; and including cough, a symptom sometimes associated with lower respiratory disease but not specific to it. Risk factors were included in models individually as well as in summary risk indices. We also evaluated whether associations between the outcomes and risk factors were stronger among doctor-diagnosed asthmatics, a subgroup expected to be more responsive to the hypothetical microbiologic contaminants represented by the risk factors. 


\section{$\underline{\text { Materials and Methods }}$}

\section{Data Collection}

Methods used in conducting the surveys, described in detail in Crandall [1996], are briefly discussed below. Between October 1992 and February 1993, the National Institute for Occupational Safety and Health received over 800 requests for health hazard evaluations (HHEs, which are investigative responses intended to identify health or safety hazards in workplaces) in office buildings. This was, in less than six months, over four times the usual annual number of requests from these settings. Due to the overwhelming number of HHEs and limited agency resources, NIOSH selected a systematic sample of 160 buildings for evaluation (of every third building among the first 480 valid requests). Between April and July 1993, NIOSH investigators used a standard protocol to collect health, building, and environmental data from a defined evaluation area within each building. A self-administered questionnaire asked about health histories and symptoms in workers. Industrial hygienists using a standardized inspection form and simple measurements recorded characteristics of the study buildings, their ventilation systems, and their indoor environments.

The present analysis includes only office buildings, excluding other types of buildings such as schools and health care facilities. Of the 105 office buildings investigated, complete data collected according to the study protocol were available from only 80 . From these 80 office buildings, 2345 workers completed the questionnaire.

\section{Outcomes}

Outcome definitions were constructed from data on four symptoms assessed in the questionnaire: three chest/lower respiratory symptoms - wheeze, shortness of breath, and chest tightness - and also cough. Cough has been grouped by some researchers with lower respiratory symptoms, but by others with upper respiratory symptoms of the nose and throat. Our analysis explores whether inclusion of cough with analyses using the three lower respiratory/chest symptoms strengthened the findings. Twenty case definitions (described in Table Ia - see footnote a) were created using combinations of these four symptoms, some with cough and some without. These definitions were restricted to "frequent work-related" (FWR) symptoms, defined as symptoms reported to occur at least once per week in the previous four weeks and to improve away from the workplace, as in Sieber [1996]. Twenty additional parallel outcomes were defined, "frequent" outcomes, not restricted to symptoms improving away from the workplace.

\section{Risk factors}

The 26 environmental risk factors used in previously reported analyses on this NIOSH data set [Sieber et al., 1996], involving either ventilation system design, ventilation system maintenance, building design, or building maintenance, were considered for the present analysis. Of those, we included only risks associated with work-related lower respiratory symptoms in the "partially adjusted" models in the previous analyses (each model contained an independent term for one environmental risk factor plus several potential personal confounding variables, but not other environmental risk factors) [Sieber et al., 1996]. We also excluded from the present analyses risk factors not considered related to potential microbiologic contamination (e.g., "outdoor air 
intake near vehicle traffic") and those with sparse data, leaving twenty dichotomous (i.e., twovalued) risk factors for analyses (Table II).

Many of the risk factors included are parts of the ventilation system that may become dirty or wet. Sound liner is a sound-absorbing porous surface lining inside the ventilation system near the supply fans. Poor pan drainage occurs when the drip pans beneath the ventilation cooling coils, which collect moisture that condenses onto the cold coils and drips down, do not drain well due to problems such as clogged or poorly designed drains, or improperly sloped pans. The air handler housing encloses the ventilation system equipment - the fans, coils, and filters. Duct liner is a usually fibrous lining inside the ducts that supply ventilation air from the air handler to the occupied spaces.

\section{Initial Modeling Strategy}

Multivariate modeling was performed using SAS version 6.12. For each of the $20 \mathrm{FWR}$ symptom outcome definitions, initial logistic regression models estimated partially adjusted odds ratios (ORs) for each of the 20 risk factors; e.g., each model included a dependent term for one outcome and independent terms for one risk factor and for four dichotomous personal variables: gender, age ( $\leq 39$ years vs. $\geq 40$ years), smoking status (never vs. ever), and asthma status (ever diagnosed by a physician). Another set of similar partially adjusted models evaluated whether relationships of risk factors to outcomes differed among those with a history of asthma by including interaction variables (building risk factor* asthma history).

Outcome definitions were ranked as follows based on estimates from models: for each risk factor, the partially adjusted odds ratios for the 20 outcome definitions were ranked and numbered (highest OR ranked as $=1$; lowest $=20$ ). (For a hypothesized protective factor, "surface dusting daily," with ORs less than 1.0, lowest ORs were ranked highest. For simplicity, all building-related factors will be referred to herein as risk factors.) A total score was calculated for each outcome by summing its ranks for all the risk factors. The outcomes with the highest mean rank for association with the set of risk factors were selected for further multivariate analysis.

We defined four subgroups of risk factors: potential sources of microbiological contaminants less than 25 feet from the outside air intake, problems with air filters (for removing particles/dust from the air supply) in the heating, ventilation, and air-conditioning (HVAC) system, dirt in the HVAC system, and moisture in the HVAC system, (see Table II). Three variables - no scheduled HVAC inspection, water damage in the workspace, and indoor surface dusting daily -were considered separately without inclusion in a sub-group. Only variables for which p-values were $<0.20$ in the initial partially adjusted models were included in this process.

In the final multivariate models, we used two alternate strategies to decrease the large number of independent variables, many highly inter-correlated: the selection of variables from preliminary models containing subgroups of risk variables, and the construction of risk factor index variables. These strategies are described in Appendix 1. 
Asthmatics as a susceptible population

To determine whether occupants with a history of diagnosed asthma were more responsive to exposures represented by the building risk factors, we attempted to add interaction variables (building risk factor * asthma history) to selected models. These included partially adjusted models for the strongest risk factors and the two highest-ranked outcome definitions, and also the final reduced models for those two outcomes. 


\section{$\underline{\text { Results }}$}

Rankings of the outcome definitions included in analyses are provided in Table I. The more stringent outcome definitions requiring more symptoms had generally higher ORs for environmental risk factors (and lower ORs for protective factors), but smaller numbers of respondents meeting the definitions. This resulted in less precision; e.g., more variability in the estimates and thus wider confidence intervals. Six of the 10 top-ranked outcomes required at least three symptoms, whereas the five outcomes that required only one symptom all ranked at the bottom (Table Ia). The most stringent case definition, requiring all four lower respiratory symptoms, had the smallest number of cases $(21$, or $0.9 \%)$ and was ranked sixth of 20 outcomes. In general, the addition of cough to symptom definitions containing only chest symptoms tended to increase the strength of associations with specific building risk factors. For example, the addition of "cough" to the case definition, 3 of 3 lower respiratory symptoms (wheeze, shortness of breath, and chest tightness), increased ORs (95\% CIs) for the risk factors "debris in air intake" and "poor pan drainage" from 3.0 (1.4-6.8) to 4.6 (1.8-12.0) and from 2.5 (1.1-6.0) to 3.9 (1.610.6), respectively. Cough was included in the top-scoring outcomes; e.g., in the top three, and six of the top 7.

Table $1 \mathrm{~b}$ shows how partially adjusted odds ratios for selected risk factors increased consistently and substantially as outcome definitions became more stringent and required more symptoms. For instance, ORs increased for debris in air intake from 1.8 to 4.9, and for poor pan drainage from 1.8 to 5.4; for the protective factor daily surface dusting, they decreased from 1.0 to 0.6.

Figure 1 shows, for selected key risk factors, the partially adjusted ORs and 95\% confidence intervals for four increasingly stringent definitions of work-related lower respiratory outcomes requiring an increasing minimum number of the four FWR symptoms. ORs increase consistently for each risk factor (or decrease consistently for the protective factor), as stringency of the outcome definition increases. Due to the smaller number of cases for the more stringent definitions, the increased odds ratios did not always translate into smaller p-values.

Relative rankings of outcome definitions from models for frequent symptoms (not shown) were essentially the same as those from models for frequent work-related symptoms. Without exception, however, each FWR outcome was more strongly related to the building risk factors than the corresponding, and less specific, frequent outcome.

Table III shows the ORs and 95\% confidence intervals from partially adjusted models of single building-related risk factors and the two outcomes with the highest mean rank for association with these risk factors. These outcomes were the top-ranked "wheeze, shortness of breath, and cough," with 27 cases, and the second-ranked "at least 3 of 4 lower respiratory symptoms," with 57 cases (also included in the previous publication by Sieber [1996], as "multiple lower respiratory symptoms"). Both these outcomes showed some association with many buildingrelated risk factors, with p-values less than 0.10 for at least half of them. Among these risk factors, the highest ORs for both outcomes were for the same three variables: "debris in air intake," "poor pan drainage," and "standing water within 25 feet of the air intake." ORs for these risk factors were, for "wheeze, shortness of breath, and cough," 5.1, 6.0, and 4.9, and for 
"at least 3 of 4 lower respiratory symptoms," 3.0, 3.6, and 4.8, respectively. The practice of daily surface dusting was equally protective for both outcomes: $\mathrm{OR}=0.5$.

Among models constructed with interaction terms for (building risk factor * asthma history), only the partially adjusted models containing single risk factors and the relatively common outcome "at least 3 of 4 FWR lower respiratory symptoms" converged. Most ORs among asthmatics were higher than among non-asthmatics, although p-values for the interaction terms all exceeded 0.05 . For example, ORs among doctor-diagnosed asthmatics vs. among nonasthmatics were, for poor pan drainage, 4.3 vs. 3.1 (p-value for interaction $=0.60$ ); for debris in air intake, 4.5 vs. 2.0 (p-value $=0.20)$; and for residue in drain pan, 3.4 vs. $1.2(p$-value $=0.08)$.

In models constructed from the risk factor subgroups listed in Table II, nine of the 11 (dichotomous) environmental variables in subgroups were associated with $\mathrm{p}$-values less than 0.20 for both outcomes (see Table II, footnote a). After including these nine variables in both final models, the reduced final models for both outcomes (top of Table IV) included 2 buildingrelated risk factors: debris in air intake and poor pan drainage. Table IV also allows comparisons, for these models, of estimated ORs for FWR outcomes and frequent outcomes.

\section{Risk Factor Indices}

Final models were also constructed including dichotomized risk factor indices and other risk factors not included in these indices (e.g., water damage, daily surface dusting). The bottom of Table IV provides estimates from this final reduced model. ORs were elevated for the dichotomized "moisture in HVAC" index for both outcomes, for water damage for "wheeze, shortness of breath, and cough," and for "no scheduled HVAC inspections" for "at least 3 of 4 symptoms." Lower risk of the outcome "at least 3 of 4 symptoms" was associated with daily surface dusting. The HVAC system cleanliness index, which included debris in air intake, was not retained in these final reduced models. The strongest relationship found $(\mathrm{OR}=4.8)$ was between the "moisture in HVAC" index and the outcome "wheeze, shortness of breath, and cough." 


\section{$\underline{\text { Discussion }}$}

The analyses reported here used models containing variations on metrics for both outcomes and risk factors, in order to evaluate the underlying relationships. The primary finding from this multivariate-adjusted analysis was the strong association between frequent, work-related multiple lower respiratory symptoms in office workers and building-related risk factors indicating moisture or contamination. "Poor pan drainage" under cooling coils in the airconditioning system, by itself or as part of the index variable for moisture in HVAC system, was the most consistently identified building-related risk, as it was included in all four final multivariate models for frequent, work-related lower respiratory symptoms. Other risks included in one or two models at most were debris in air intake, water damage in occupied spaces, and no scheduled HVAC inspections. The correlations between these risks make it difficult to know which if any represent the true underlying risks, but the findings point more towards moisturerelated risks. This is presumably because the moisture supports microbiologic growth on surfaces over which the ventilation air supplied to the building flows.

Analyses here adjusted simultaneously for both personal factors (including smoking status and asthma history) and other building-related risk factors. One outcome included in analyses here, "at least three of four frequent, work-related lower respiratory symptoms," was also included in analyses of the same data reported by Sieber [1996] as "multiple lower respiratory symptoms." For this outcome, Sieber reported relative risks for a list of risk factors, each adjusted only for age and gender but not for other personal factors or other building-related risk factors. Analyses here thus extend analyses reported by Sieber [1996]. The analyses reported here also differ from those of Sieber in several other ways: including only building-related risk factors hypothetically related to microbiologic contamination; creating and comparing multiple variations in outcome definitions; and using several modeling strategies to adjust for the large number of intercorrelated environmental risk factors.

Among the four final sets of model estimates, the single most consistent risk factor was "poor pan drainage" (or a "moisture in HVAC" index almost entirely determined by values of this variable), with adjusted ORs ranging from 2.6 to 4.8 , and all 95\% lower confidence limits above 1.0. "Debris in air intake" was included in the two models of dichotomous building-related risk factors. In the model with index variables, however, this risk was included in the "dirt in HVAC" index, which did not appear in the final models. Constructing the index variable for dirt in HVAC out of seven single variables apparently diluted the contribution of the "debris in air intake" variable sufficiently to exclude the entire index variable from the model. Instead, one model contained two different variables: "no scheduled HVAC inspections" and "daily surface dusting" (a protective factor), and the other model contained "water damage in occupied space." Presumably these factors contribute to risk but are correlated with the debris in air intake variable, contributing significantly only when the latter was omitted.

Three risk factors included in the final models - "poor pan drainage" (or the "moisture in HVAC" index), "debris in air intake," and "no scheduled HVAC inspections" - would increase the risk of soiling and moisture in the HVAC system, consequent amplification of microbiological organisms there, and dissemination of their products - allergens, irritants, or 
toxins -- through the ventilation system. The other risk factors identified - water damage in occupied spaces: and lack of "daily surface dusting" - indicate risk of particles or moisture in the occupied spaces. Multiple previous studies have found connections between indoor dust and microbiologic contaminants [e.g., Gravesen et al., 1986]. Additional research is necessary to identify more precisely the indoor exposures underlying these findings.

A second set of key findings from this analysis relates to the pattern of stronger associations found for more stringent outcome definitions. Torén [1993] recommended that analytic epidemiologic studies evaluating risks for a health effect use questions with a very high (>99\%) specificity even if sensitivity is low, to prevent dilution of the risk estimates by false positives [Copeland et al., 1977]. The magnitude of partially adjusted ORs for the 20 primary outcome definitions assessed (bottom of Table I) roughly paralleled the stringency of the definitions. ORs for the six outcome definitions requiring only one symptom were the lowest ranked outcomes. The stronger association of stringent definitions with building risk factors helps corroborate the occurrence of an underlying, relatively severe health response, involving three or four workrelated lower respiratory symptoms at least weekly, among more than $2 \%$ of respondents.

The final reduced model for "FWR wheeze, shortness of breath, and cough" included only 27 cases with six independent variables, or fewer than five cases per variable. The final model for "at least three of four FWR breathing symptoms," with 57 cases and six independent variables, or about 10 cases per variable, is a more stable model. The potential advantage for statistical power of more sensitive but rarer outcome definitions more strongly associated with risk factors may thus be outweighed by limitations in modeling, and also by reduced precision. Replication in a larger population will be necessary to identify outcome definitions that best balance sensitivity and precision in identifying building-related risks, e.g., in these data, "at least three of four FWR breathing symptoms" or "tight chest and cough" (bottom of Table I).

The third finding of note was the tendency for stronger risk/response relations among doctordiagnosed asthmatics for building-related risk factors. The greatly increased risk (ORs of about 7- 9) for work-related lower respiratory symptoms among those with a history of asthma, relative to those without, could have resulted from reporting bias among concerned building occupants with asthma. More telling, however, is the consistent tendency towards increased sensitivity to microbiologic risk factors (of which subjects were not aware) among doctor-diagnosed asthmatics. For the largest difference reported here - for association of "residue in drain pan" with "at least three or four FWR lower respiratory symptoms" - the estimated ORs of 3.4 among asthmatics vs. 1.2 among non-asthmatics ( $\mathrm{p}=0.08$ for this difference) suggest that virtually all the excess risk occurred among asthmatics. Small sample size limited these analyses. Furthermore, misclassification of true current asthmatics, by the relatively nonspecific question on asthma diagnosis "ever" by a physician, would cause underestimation of differences found. The apparent increased sensitivity of diagnosed asthmatics to risks for microbiologic contamination in the buildings may represent increased response among occupants with pre-existing asthma, or response by occupants with asthma caused by the building to continuation of the sensitizing exposures. Replication and clarification of this critical finding in larger populations is essential. 


\section{Limitations of study}

The office buildings included in this analysis, all buildings for which health hazard investigations had been requested, may differ from other buildings. Findings thus cannot be directly extrapolated to office buildings in general. In particular, estimates of symptom prevalence from these data are higher than in other US buildings [Brightman et al., 1999; Malkin et al., 1996]. The presence of environmental risks and resulting health effects may be higher in these buildings; the occupants' concerns about their indoor environments in these investigated buildings may have caused relative over-reporting of symptoms experienced while in the building; or both of these could be true. However, concern could not create or increase associations of symptoms with risk factors of which respondents were unaware, such as conditions within the ventilation systems. Thus, given other limitations of the study, these findings are likely to be relatively valid in the population studied. On the other hand, to the extent that the inaccuracies of subjective reporting of symptoms increased random misclassification of the outcomes, this would reduce estimates of true relationships toward the null, and cause underestimates of true risks in this population.

The most straightforward generalization of these findings is to other U.S. office buildings with recognized air quality problems. These findings suggest conditions in such buildings to address to prevent or reduce symptoms. "Complaint" office buildings, although the frequency of their occurrence has not been quantified, represent an important set of buildings with public health importance. Findings here on prevalence of building-related symptoms clearly cannot be extrapolated to office buildings in general, but the findings on relationships of risks to outcomes may turn out to hold in other office buildings as well. More of these building may have environmental risks and adverse exposures than buildings in general, but in theory, the relationships found of risks to effects should apply to other buildings with those risks as well. Any general overreporting of symptoms within the complaint buildings studied should not create a bias that prevents generalization; because this general overreporting would tend to cancel itself out in the comparisons between the buildings.

The analyses described here, which build on findings from previous analyses of the same data [Sieber et al., 1996], were intended to explore patterns of association and generate hypotheses for re-testing and confirmation in other data. The findings here should be considered in this light. Nevertheless, although this analysis included "multiple comparisons," chance associations are unlikely to explain the present findings. For instance, in partially adjusted models for the two highest ranking outcomes, nine and seven of the 20 risk factors, respectively, had lower $95 \%$ confidence limits above 1.0 (Table III), compared to one expected for each model by chance alone. Furthermore, for the four example risk factors listed at the bottom of Table I, lower 95\% confidence limits for association of these risk factors with the 20 outcomes were above 1.0 for 43 of 60 estimates, and upper $95 \%$ confidence limits for the protective factor were below 1.0 for 4 of 20. These 47 statistically significant associations among 80 comparisons are much greater than the four expected by chance alone.

For common health outcomes such as many building-related symptoms, estimated ORs may differ substantially from risk ratios (defined as the outcome risk among the exposed divided by the risk among the unexposed) and therefore are less useful for estimating additional risk related 
to exposures. Because the prevalence of the two outcomes in final models were low (1.1 and $2.3 \%$ ), the adjusted ORs will only slightly overestimate adjusted risk ratios (by $2-4 \%$ ) [Zhang and $\mathrm{Yu}, 1998]$.

\section{Implications}

Although work-related lower respiratory symptoms reported in industrial or agricultural settings are considered potential indicators of work-related disease, such symptoms in non-industrial indoor environments are generally accorded little clinical significance because of the presumed lack of causal exposures. Yet multiple reports have described serious respiratory BRI, including hypersensitivity pneumonitis and asthma, caused by building or HVAC-related moisture and mold in workplaces [Hoffman et al., 1993; Jarvis and Morey, 2001; Kreiss, 1989; Seuri et al., 2000; Thörn et al., 1996; Woodard et al., 1988].

Investigators of health complaints in buildings often tally and report only the most commonly reported symptoms (generally headache, fatigue, or eye irritation) without realizing that these are generally the most commonly reported symptoms in any building [Brightman et al., 1999; Mendell et al., 1996]. This almost invariably excludes the lower respiratory symptoms. Yet this exclusion, as suggested in the findings here, may hide an important component of the biologic response in a key susceptible subpopulation. The symptoms studied here may represent unrecognized subclinical manifestations of known building-related disease such as asthma or hypersensitivity pneumonitis [Kreiss, 1989].

The findings here, although requiring replication, suggest that building-related respiratory health effects may occur without recognition among a proportion of indoor workers with moisture- or contaminant-related exposures. History of asthma, whether diagnosed prior to working in the building or initially caused by exposures in the building, may confer heightened sensitivity to these exposures. Replication of the findings reported here could lead to earlier identification of indoor workplaces and workers at increased risk of work-related respiratory health effects. At present, BRI cases found in indoor work environments have almost without exception been identified through follow-up of clinically diagnosed index cases, traced back to the indoor workplace by astute clinicians [Hoffman et al., 1993; Thörn et al., 1996; Woodard et al., 1988].

In summary, our analyses found several conditions in buildings or ventilation systems suggestive of excessive moisture or poor maintenance to be risks for increased work-related lower respiratory symptoms among occupants - particularly, poor drainage in the air-conditioning drip pans, but also debris in the ventilation air intake, no scheduled ventilation system inspections, water damage in occupied spaces, and lack of daily surface dusting. The risks were higher for more stringent and severe outcome definitions requiring multiple symptoms with cough, and for symptoms improving away from work, suggesting that these were more specific metrics for the underlying health effect. The risks also tended to be greater among previously diagnosed asthmatics. Although office buildings are not usually considered to pose risks for lower respiratory health, poor design or maintenance of ventilation systems and occupied spaces in these office settings may result in exposures that cause or exacerbate lower respiratory health problems. 
Analyses of data from representative sets of buildings, rather than from buildings with recognized air quality problems, are needed to quantify the occurrence of these risk factors and confirm the relationships found here. Even if low proportions of buildings have the risk factors evaluated here, the absolute numbers of U.S. workers at risk among the almost 70 million in indoor environments may be of public health significance. Future research on occupants reporting multiple lower respiratory symptoms exacerbated within buildings, including a focus on susceptible subgroups such as asthmatics, may help identify more specific environmental risks for building-related respiratory disease. Etiologic research into other poorly characterized health effects attributed to the environment may benefit from analyses using alternate metrics of symptom-based outcome measures for disease processes of interest, and indicators for suspect but poorly characterized exposures. 


\section{References}

Bornehag CG, Blomquist G, Gyntelberg F, Jarholm B, Malmberg P, Nordvall L, Nielsen A, Pershagen G, Sundell J. 2001. Dampness in buildings and health: Nordic interdisciplinary review of the scientific evidence on associations between exposure to "dampness" in buildings and health effects (NORDDAMP). Indoor Air 11: 72-86.

Brightman HS, Wallace LA, Sieber WK, McCarthy JF, Spengler JD. 1999. Comparing symptoms in Unites States office buildings. In: Raw GA, C.; Warren, P. editor. Indoor Air '99: Proceedings of the 8th International Conference on Indoor Air Quality and Climate Edinburgh, Scotland: Construction Research Communications Ltd. p 847-852.

Burge S, Hedge A, Wilson S, Bass JH, Robertson A. 1987. Sick building syndrome: a study of 4373 office workers. Ann Occup Hyg 31: 493-504.

Copeland KT, Checkoway H, McMichael AJ, Holbrook RH. 1977. Bias due to misclassification in the estimation of relative risk. Am J Epidemiol 105: 488-495.

Crandall MS, Sieber WK. 1996. The National Institute for Occipational Safety and Health indoor environmental evaluation experience. Part one: building environment evaluation. Appl Occup Environ Hyg 11: 533-539.

Gravesen S, Larsen L, Gyntelberg F, Skov P. 1986. Demonstration of microorganisms and dust in schools and offices. An observational study of non-industrial buildings. Allergy 41: 520-525.

Gyntelberg F, Suadicani P, Nielsen JW, Skov P, Valbjorn O, Nielsen PA, Schneider T, Jorgensen O, Wolkoff P, Wilkins CK, Gravesen S, Norn S. 1994. Dust and the sick building syndrome. Indoor Air 4: 223-238.

Hodgson MJ, Morey PR, Simon JS, Waters TD, Fink JN. 1987. An outbreak of recurrent acute and chronic hypersensitivity pneumonitis in office workers. Am J Epidemiol 125: 631-638.

Hoffman RE, Wood RC, Kreiss K. 1993. Building-related asthma in Denver office workers. Am J Public Health 83: 89-93.

Jaakkola JJ, Miettinen P. 1995. Type of ventilation system in office buildings and sick building syndrome. Am J Epidemiol 141: 755-765.

Jarvis JQ, Morey PR. 2001. Allergic respiratory disease and fungal remediation in a building in a subtropical climate. Appl Occup Environ Hyg 16: 380-388.

Kreiss K. 1989. The epidemiology of building-related complaints and illness. Occup Med 4: 575592. 
Malkin R, Wilcox T, Sieber WK. 1996. The National Institute for Occupational Safety and health indoor environmental evaluation experience. Part two: symptom prevalence. Appl Occup Environ Hyg 11: 540-545.

Mendell MJ. 1993. Non-specific symptoms in office workers: A review and summary of the epidemiologic literature. Indoor Air 3: 227-236.

Mendell MJ, Fisk WJ, Deddens JA, Seavey WG, Smith AH, Smith DF, Hodgson AT, Daisey JM, Goldman LR. 1996. Elevated symptom prevalence associated with ventilation type in office buildings. Epidemiology 7: 583-589.

Mendell MJ, Sieber WK, Dong MX, Malkin R, Wilcox T. 1996. Symptom prevalence distributions in U.S. office buildings investigated by NIOSH for indoor environmental quality compalints. Indoor Air '96: Proceedings of the 7th International Conference on Indoor Air Quality and Climate Nagoya, Japan. p 877-882.

Ruotsalainen R, Jaakkola N, Jaakkola JJ. 1995. Dampness and molds in day-care centers as an occupational health problem. Int Arch Occup Environ Health 66: 369-374.

Seuri M, Husman K, Kinnunen H, Reiman M, Kreus R, Kuronen P, Lehtomaki K, Paananen M. 2000. An outbreak of respiratory diseases among workers at a water-damaged building--a case report. Indoor Air 10: 138-145.

Sieber WK, Stayner LT, Malkin R, Peterson MR, Mendell MJ, Wallingford KMC, M. S., Wilcox TG, Reed L. 1996. The National Institute for Occupational Safety and Health indoor environmental evaluation experience. Part Three: Associations between environmental factors and self-reported health conditions. Applied Occupational and Environmental Hygiene. 11: 1387-1392.

Teeuw KB, Vandenbroucke-Grauls CM, Verhoef J. 1994. Airborne gram-negative bacteria and endotoxin in sick building syndrome. A study in Dutch governmental office buildings. Arch Intern Med 154: 2339-2345.

Thörn A, Lewne M, Belin L. 1996. Allergic alveolitis in a school environment. Scand J Work Environ Health 22: 311-314.

Torén K, Brisman J, Jarvholm B. 1993. Asthma and asthma-like symptoms in adults assessed by questionnaires. A literature review. Chest 104: 600-608.

Woodard ED, Friedlander B, Lesher RJ, Font W, Kinsey R, Hearne FT. 1988. Outbreak of hypersensitivity pneumonitis in an industrial setting. JAMA 259: 1965-1969.

Zhang J, Yu KF. 1998. What's the relative risk? A method of correcting the odds ratio in cohort studies of common outcomes. JAMA 280: 1690-1691. 


\section{Acknowledgements}

We would like to thank Mike Crandall and Robert Malkin, who helped coordinate the NIOSH Health Hazard Evaluation data collection effort in 1993, the more than 40 others who collected or organized the data, and the other members of the group that planned the initial analyses of these data, including Ken Wallingford, Leslie Stayner, and Larry Reed. This work was supported by the Centers for Disease Control, National Institute for Occupational Safety and Health,and by the Assistant Secretary for Energy Efficiency and Renewable Energy, Building Technology Program of the U.S. Department of Energy under Contract No. DE-ACO3$76 \mathrm{SF} 00098$. 


\section{Appendix 1. Details of preliminary strategies for constructing multivariate models}

\section{Preliminary models with subgroups of risk factors as independent variables}

For each of the two selected outcomes, an initial multivariate model was constructed for each subgroup of risk factors. Each model included the risk factors within the subgroup and the personal covariates for gender, age, smoking, and asthma status. From each subgroup, variables for which $\mathrm{p}>0.20$ were eliminated sequentially, except when their removal changed the estimates for another risk factor by more than $15 \%$.

For each outcome, a final model was created containing all the risk factor variables from the reduced subgroup models, plus the ungrouped risk factor variables, along with gender, age, smoking, and asthma status. This full model was then reduced by sequential elimination of terms for which $\mathrm{p}>0.10$, except when their removal changed the estimates of another risk factor by more than $15 \%$.

\section{Risk factor index variables}

In the second model reduction strategy, a continuous index variable was created for each of the four risk factor subgroups described above (listed in Table II). Each subgroup index for a building was calculated by summing the number of risk factors (independent variables) within the subgroup that were present in that building. The index variables (and ranges of possible scores per building) were - microbiological sources less than 25 feet from the outside air intake (range 0-3), problems with the particle filtration (range 0-4), dirt in the HVAC system (range 07), and moisture in the HVAC system (range 0-2). Dichotomous variables, evaluated separately, were retained for the following: no scheduled HVAC maintenance, daily surface dusting, and water damage in the workspace.

The continuous indices were evaluated for the two selected outcomes, with adjustment for personal variables. To evaluate whether indices were linear each was categorized into low, medium, and high and modeled with indicator variables. The low (reference) category was defined as having none of the problems in that category; medium and high categories each contained half the remaining observations. Simpler dichotomized variables were also created for each index (any problems within a specific sub-category vs. none of the problems in the category). 
Table I.a. Ranking of 20 lower respiratory symptom-based outcome definitions ${ }^{\mathrm{a}}$ by mean rank for association with 20 buildingrelated risk factors ${ }^{\mathrm{b}}$ in partially adjusted logistic regression models ${ }^{\mathrm{c}}$

I.b. Partially-adjusted odds ratios for associations of example risk factors with 20 outcomes

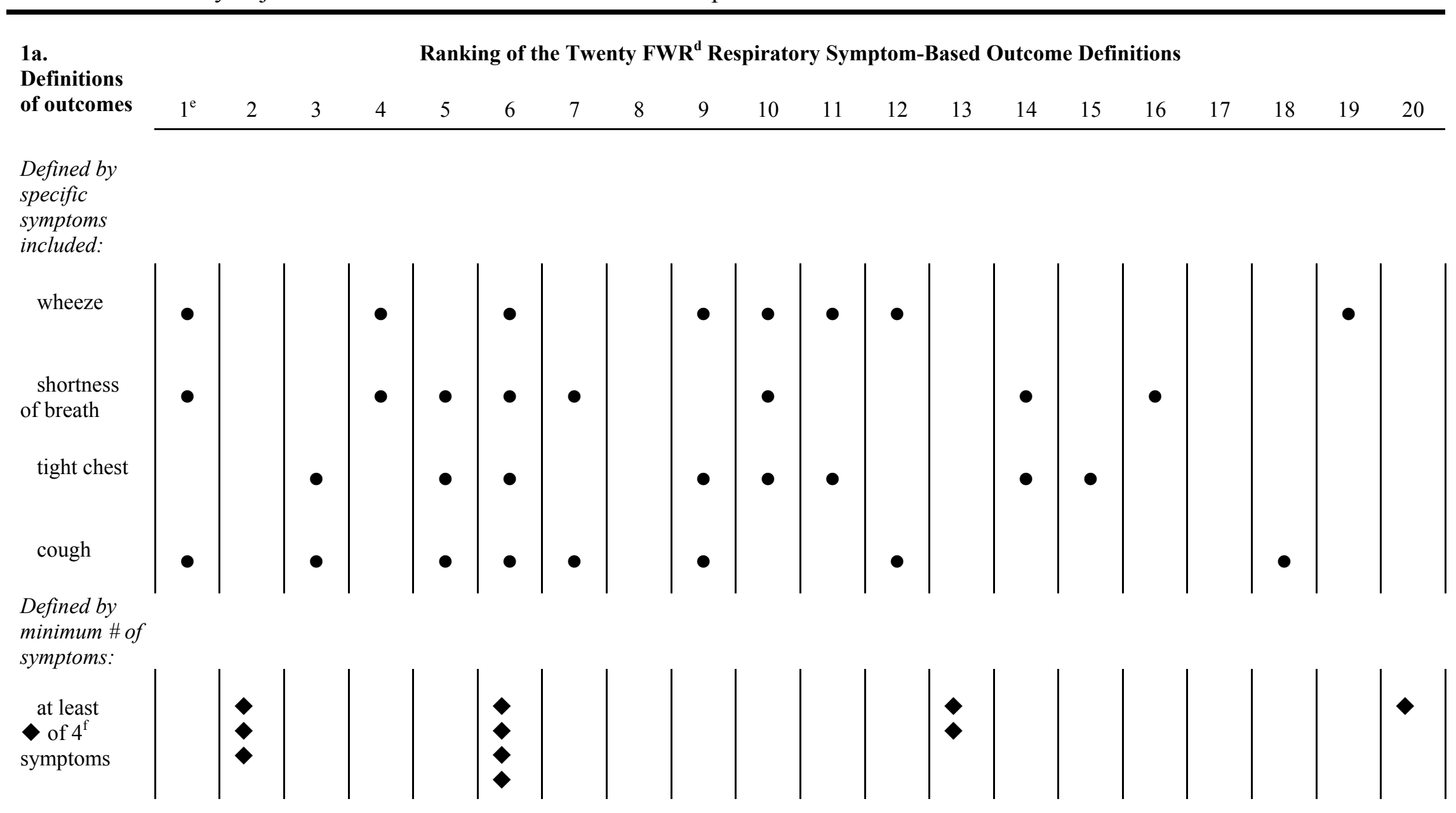




\section{1b. Example} risk factors:

Partially Adjusted ORs ${ }^{\mathrm{c}, \mathrm{h}}$ for Different Outcome Definitions

\begin{tabular}{|c|c|c|c|c|c|c|c|c|c|c|c|c|c|c|c|c|c|c|c|c|}
\hline $\begin{array}{l}\text { debris in } \\
\text { air intake }\end{array}$ & 4.9 & 3.2 & 3.2 & 2.9 & 3.6 & 4.6 & 3.2 & 2.6 & 4.3 & 3.0 & 3.4 & 3.5 & 2.4 & 2.3 & 2.6 & 1.9 & 2.2 & 1.8 & 2.3 & 1.8 \\
\hline $\begin{array}{l}\text { poor pan } \\
\text { drainage }\end{array}$ & 5.4 & 3.1 & 2.6 & 3.3 & 3.7 & 3.9 & 3.9 & 2.5 & 3.0 & 2.5 & 1.9 & 2.6 & 2.0 & 2.4 & 1.9 & 2.5 & 1.9 & 1.8 & 1.9 & 1.8 \\
\hline $\begin{array}{l}\text { residue in } \\
\text { drain pan }\end{array}$ & 2.1 & 1.7 & 1.7 & 1.8 & 1.7 & 1.9 & 1.7 & 1.5 & 1.8 & 1.7 & 1.5 & 1.7 & 1.5 & 1.4 & 1.4 & 1.3 & 1.3 & 1.2 & 1.3 & 1.1 \\
\hline $\begin{array}{l}\text { daily } \\
\text { surface } \\
\text { dusting }\end{array}$ & 0.6 & 0.6 & 0.6 & 0.6 & 0.6 & 0.5 & 0.5 & 0.7 & 0.5 & 0.7 & 0.6 & 0.6 & 0.7 & 0.8 & 0.8 & 0.7 & 0.8 & 1.0 & 0.8 & 1.0 \\
\hline $\begin{array}{l}\text { Number of } \\
\text { cases: }\end{array}$ & 27 & 57 & 65 & 43 & 36 & 21 & 57 & 88 & 27 & 30 & 44 & 46 & 133 & 61 & 150 & 116 & 241 & 217 & 93 & 365 \\
\hline
\end{tabular}

a Each column specifies one symptom-based outcome definition, ranked from 1-20. Each of the 20 ranked definitions involves either a specific set of symptoms (e.g., the \#1 ranked outcome is "wheeze, shortness of breath, and cough") or a minimum number of symptoms (e.g., \#2 ranked is "at least 3 of four respiratory symptoms"). Note that for the definitions ranked 6 and 10, either type of description can be used, because "at least 3 of 3 symptoms" is equivalent to "wheeze, shortness of breath and tight chest."

b See Table II for the list of environmental risk factors

c Adjusted for age, gender, smoking status, and asthma status

d Frequent, work-related

e This column, for example, says that the combination of frequent work-related wheeze, shortness of breath, and cough had, relative to the 20 outcome definitions assessed, the highest mean rank for association with 20 building-related risk factors, in partially adjusted models.

$\mathrm{f}$ the number of symptoms out of the 4: FWR wheeze, shortness of breath, tight chest, and cough. "At least 3 of 4 FWR lower respiratory symptoms" was ranked \#2 of 20 outcomes; "4 of 4" was ranked \# 6; "at least 2 of 4" was ranked \#13; and "at least 1 of 4 " was ranked \#20.

$\mathrm{g}$ the number of symptoms out of the 3: FWR wheeze, shortness of breath, and tight chest. "At least 2 of 3 FWR lower respiratory symptoms" was ranked \# 8 of 20 outcomes; "3 of 3" was ranked \#10; and "at least 1 of 3" was ranked \#17.

h Number in bold type indicates OR with p-value \#0.05. 
Table II. Independent variables used for building-related risks in analyses, either as components of subgroups or as components of index variables ${ }^{\mathrm{a}}$

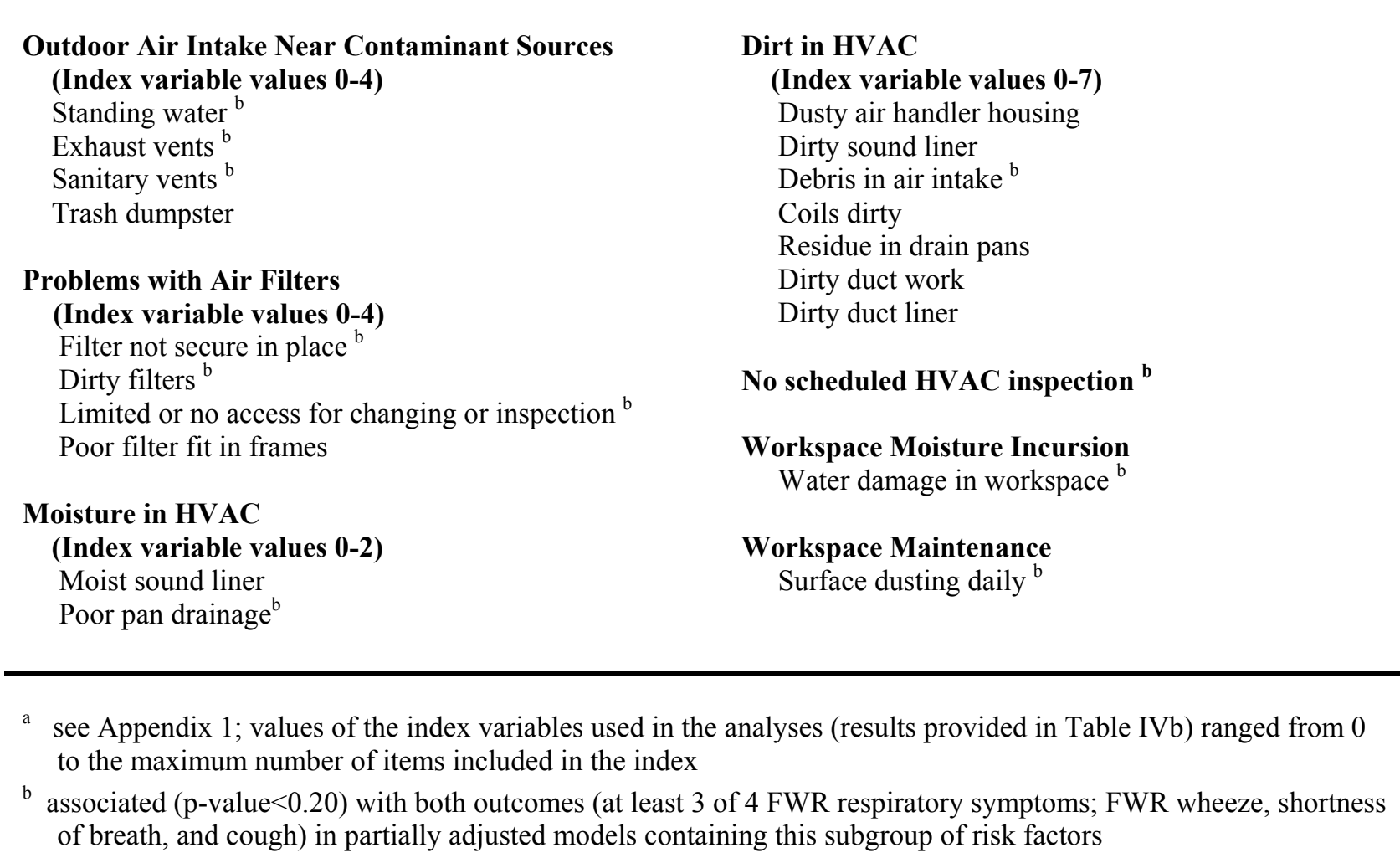


Table III. Odds ratios (OR) and 95\% confidence intervals (CIs) for building risk factors from partially adjusted models ${ }^{\mathrm{a}}$

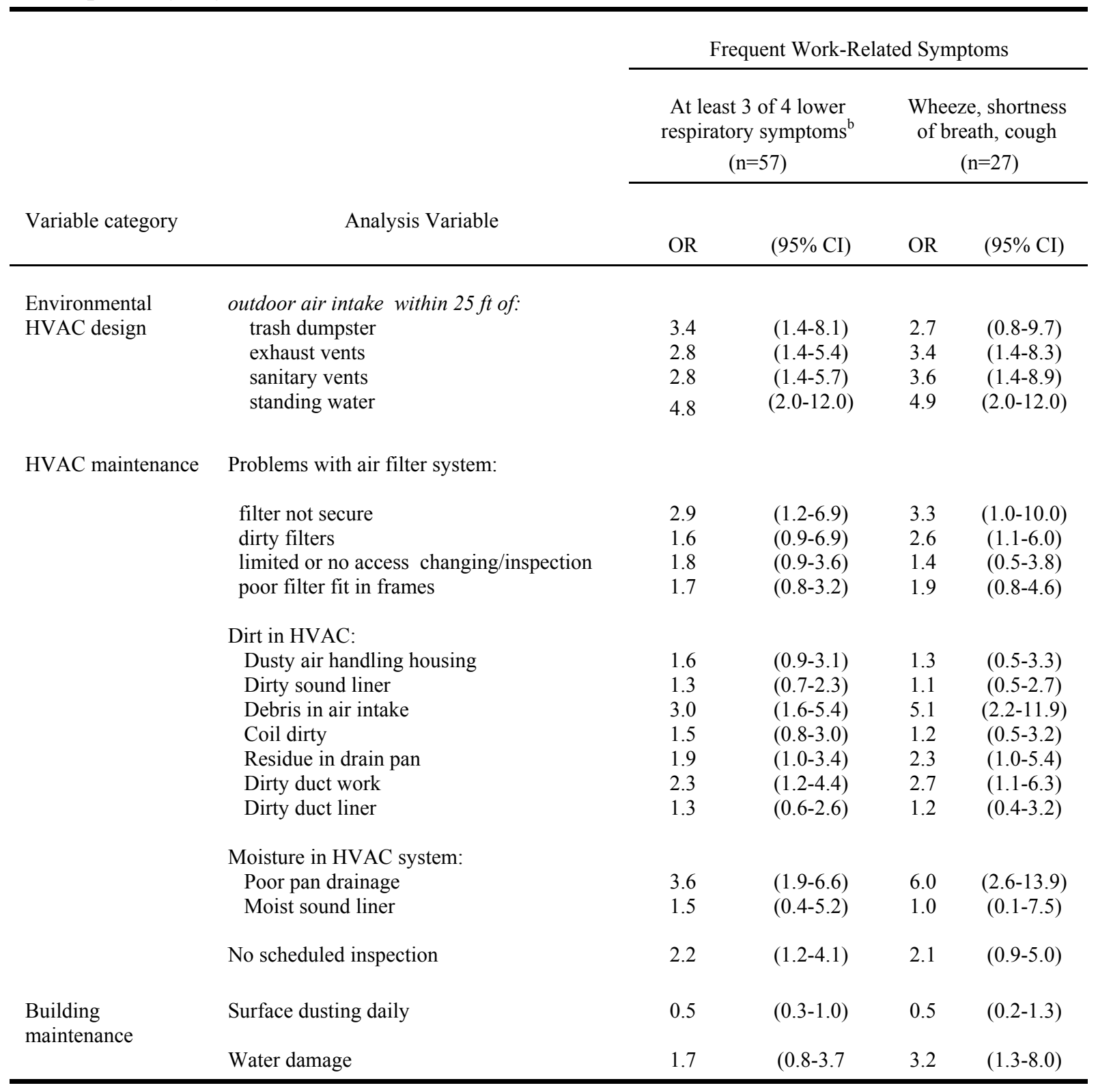

a All models adjusted for age, gender, smoking status, and asthma status

b Wheeze, shortness of breath, tight chest, or cough 
Table IV. Odds ratios ${ }^{\mathrm{a}}(\mathrm{OR})$ and $95 \%$ confidence intervals (CI) for dichotomous building risk factors and for building risk factor indices, from final multivariate models ${ }^{\mathrm{b}}$

\begin{tabular}{|c|c|c|c|c|c|c|c|c|c|}
\hline \multirow[b]{3}{*}{$\begin{array}{l}\text { Variable } \\
\text { Category }\end{array}$} & \multirow[b]{3}{*}{ Analysis Variable } & \multicolumn{4}{|c|}{ Frequent Work-Related Respiratory Symptoms } & \multicolumn{4}{|c|}{ Frequent Respiratory symptoms } \\
\hline & & \multicolumn{2}{|c|}{$\begin{array}{l}\text { At least } 3 \text { of } 4 \\
\text { symptoms }\end{array}$} & \multicolumn{2}{|c|}{$\begin{array}{l}\text { Wheeze, shortness of } \\
\text { breath, and cough }\end{array}$} & \multicolumn{2}{|c|}{$\begin{array}{l}\text { At least } 3 \text { of } 4 \\
\text { symptoms }\end{array}$} & \multicolumn{2}{|c|}{$\begin{array}{l}\text { Wheeze, shortness of } \\
\text { breath, and cough }\end{array}$} \\
\hline & & OR & $(95 \% \mathrm{CI})$ & OR & $(95 \% \mathrm{CI})$ & OR & $(95 \% \mathrm{CI})$ & OR & $(95 \% \mathrm{CI})$ \\
\hline \multicolumn{10}{|c|}{$\begin{array}{l}\text { (a) Models with all risk factor variables } \\
\text { dichotomous }\end{array}$} \\
\hline \multirow[t]{2}{*}{$\begin{array}{l}\text { Building Risk } \\
\text { Factors }\end{array}$} & $\begin{array}{l}\text { Dirt in HVAC variables: } \\
\text { Debris in air intake }\end{array}$ & 2.0 & $(1.0-3.9)^{2}$ & 3.6 & $(1.4-9.4)^{2}$ & 1.8 & $(1.1-3.0)^{2}$ & 2.3 & $(1.2-4.4)^{2}$ \\
\hline & $\begin{array}{l}\text { Moisture in HVAC variables: } \\
\text { Poor pan drainage }\end{array}$ & 2.6 & $(1.3-5.2)^{2}$ & 2.8 & $(1.1-7.4)^{2}$ & 1.6 & $(1.0-2.8)^{2}$ & 1.8 & $(0.9-3.6)^{2}$ \\
\hline Personal & $\begin{array}{l}\text { female gender } \\
\text { age over } 40 \text { years } \\
\text { ever smoked } \\
\text { doctor diagnosed asthma }\end{array}$ & $\begin{array}{l}3.0 \\
2.3 \\
1.2 \\
8.0\end{array}$ & $\begin{array}{l}(1.4-6.6)^{2} \\
(1.2-4.5)^{2} \\
(0.6-2.1) \\
(4.4-14)^{2}\end{array}$ & $\begin{array}{l}3.2 \\
2.2 \\
1.8 \\
6.9\end{array}$ & $\begin{array}{l}(1.0-9.8)^{2} \\
(0.8-5.9)^{2} \\
(0.7-4.2) \\
(3.0-16)^{2}\end{array}$ & $\begin{array}{l}3.0 \\
1.5 \\
1.6 \\
10.0\end{array}$ & $\begin{array}{c}(1.7-5.1)^{2} \\
(1.0-2.4)^{2} \\
(1.0-2.4)^{2} \\
(6.6-15)^{2}\end{array}$ & $\begin{array}{c}1.6 \\
2.2 \\
2.0 \\
10.3\end{array}$ & $\begin{array}{l}(0.9-2.9)^{2} \\
(1.1-4.3)^{2} \\
(1.1-3.6)^{2} \\
(5.9-18)^{2}\end{array}$ \\
\hline \multicolumn{10}{|c|}{ (b) Models with risk factor index variables } \\
\hline \multirow{4}{*}{$\begin{array}{l}\text { Building Risk } \\
\text { Factors }\end{array}$} & Moisture in HVAC (index) & 2.6 & $(1.4-4.8)^{2}$ & 4.8 & $(2.0-12)^{2}$ & & & & \\
\hline & No scheduled HVAC inspections & 1.7 & $(0.9-3.3)^{2}$ & - & -- & & & & \\
\hline & Water damage in occupied space: & -- & -- & 2.4 & $(0.9-6.2)^{2}$ & & & & \\
\hline & Daily surface dusting & 0.5 & $(0.3-1.1)^{2}$ & -- & --- & & & & \\
\hline Personal & $\begin{array}{l}\text { female gender } \\
\text { age over } 40 \text { years } \\
\text { ever smoked }\end{array}$ & $\begin{array}{l}2.9 \\
2.0 \\
1.2\end{array}$ & $\begin{array}{c}(1.3-6.4)^{2} \\
(1.0-4.0)^{2} \\
(0.7-2.2)\end{array}$ & $\begin{array}{l}2.9 \\
2.0 \\
1.7\end{array}$ & $\begin{array}{l}(1.0-9.1)^{2} \\
(0.8-5.4) \\
(0.7-4.2)\end{array}$ & & & & \\
\hline
\end{tabular}


a ORs for building-related risk factors for which $\mathrm{p}$-value $<0.10$ are shown, and in bold type if $\mathrm{p}$-value $<0.05$.

b All models corrected for age, gender, smoking status, and asthma status 
Figure 1. Odds Ratios and $95 \%$ confidence intervals for the association of building-related risk factors with frequent workrelated (FWR) lower respiratory symptom-based outcome definitions of increasing stringency, in partially adjusted models, from 1993 NIOSH Health Hazard Evaluations

\section{Figure 1 Legend:}

$\geq 1$ of 4 FWR respiratory symptoms ${ }^{b}$

$\geq 2$ of 4 FWR respiratory symptoms

$\geq 3$ of 4 FWR respiratory symptoms

4 of 4 FWR respiratory symptoms

\section{Figure 1 footnotes:}

a Adjusted for age, gender, smoking
$\mathrm{b}$ Frequent, work-related wheeze, shortness of breath, tight chest, or cough 


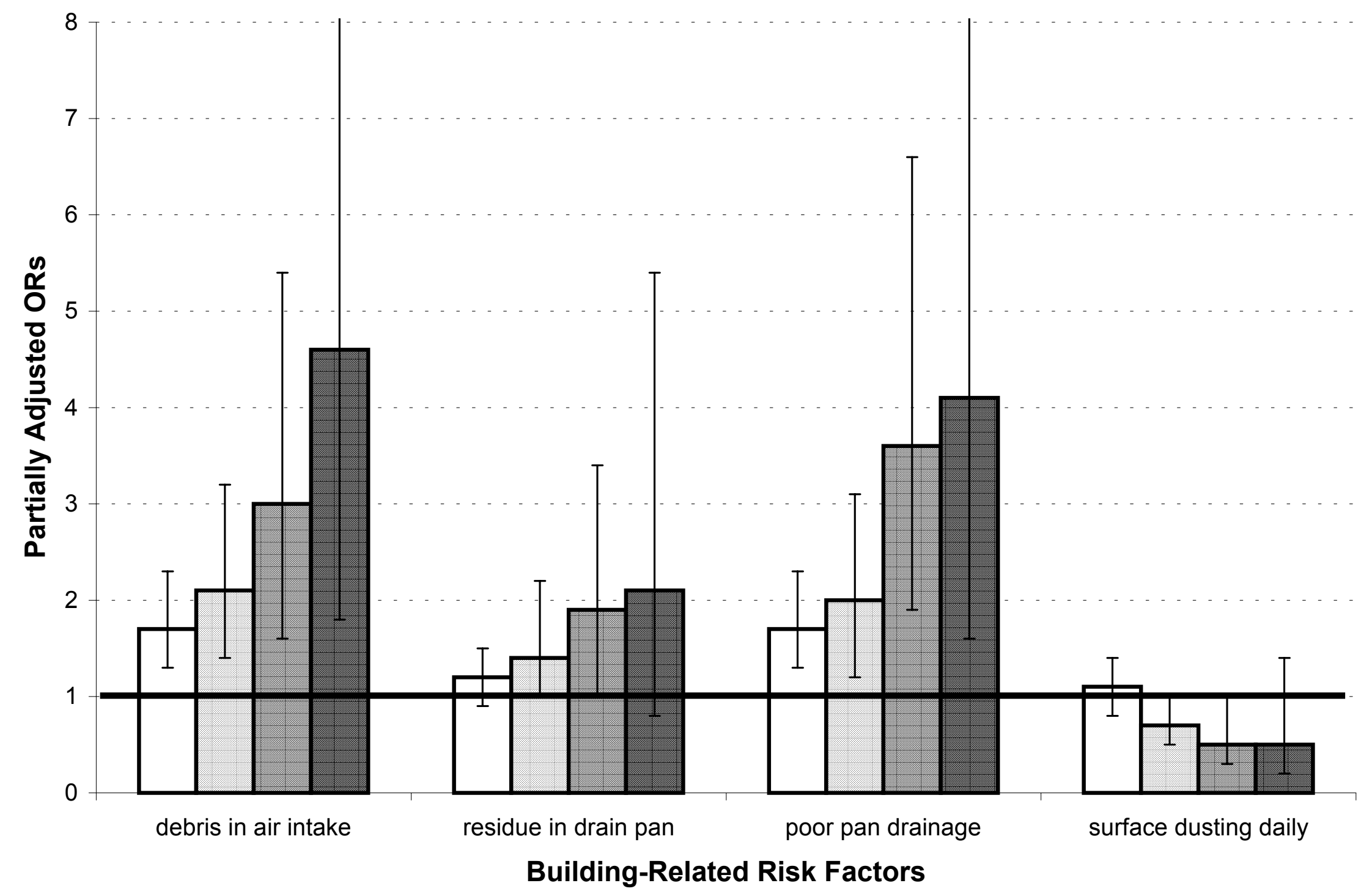

Page 24 
Page 25 